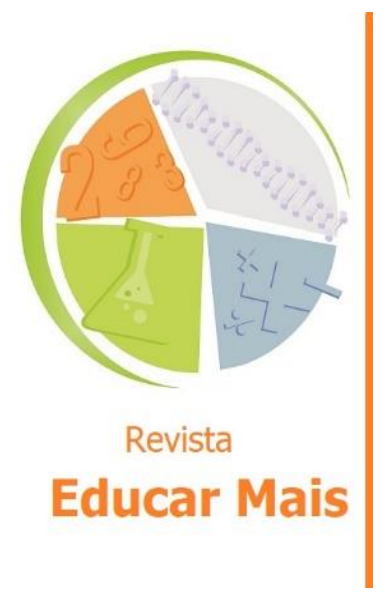

\title{
Trabalho pedagógico em tempos de pandemia: realidade vivenciada por professores município de Humaitá-AM
}

\author{
Pedagogical work in times of pandemic: the reality experienced by \\ teachers in the municipality of Humaitá-AM
}

\section{Trabajo pedagógico en tiempos de pandemia: realidad vivida por profesores municipio de Humaitá-AM}

Eulina Maria Leite Nogueira ${ }^{1}$; Zilda Gláucia Elias Franco²; Marinez dos Santos de Paula3; Welton de Araújo Prata ${ }^{4}$

\section{RESUMO}

O Brasil e o mundo estão passando por uma grave crise sanitária, provocada pela COVID-19, que tem afetado todos os setores da sociedade, seja de saúde, economia, social, cultural e educacional. No Brasil, a pandemia tem afetado diretamente o setor educacional, seja na suspensão das aulas presenciais, seja na condição de vida dos profissionais da educação. O objetivo deste artigo é analisar como estão sendo desenvolvida as práticas pedagógicas nesse período de pandemia e como isso afeta a saúde emocional dos professores da rede municipal de Humaitá-AM. Para a realização desta pesquisa, foi adotada uma metodologia de abordagem qualiquantitativa, com a aplicação de entrevista virtual, além do uso de formulário disponível no Google. As entrevistas foram feitas com diversos grupos de professores, por escolas, no total de nove escolas da área urbana do município. Essas entrevistas foram destinadas a professores que atuam do $1^{0}$ ao $5^{\circ}$ do ensino fundamental. Constatou-se que a maioria dos professores se encontra desenvolvendo atividades pedagógicas, sem, contudo, receber qualquer tipo de capacitação ou auxílio com o uso da internet para o desenvolvimento das atividades. A grande maioria dos professores considera que o modelo remoto não tem contribuído de forma positiva para a aprendizagem dos alunos. Muitos professores afirmaram estar em alto grau de estresse, medo e depressão.

Palavras-chave: Pandemia, Educação, Prática pedagógica.

\section{ABSTRACT}

Brazil and the world are going through a serious health crisis, caused by COVID-19, which has affected all sectors of society, health, economy, social, cultural, and educational. In Brazil, the pandemic has directly affected the educational sector, whether in the suspension of face-to-face classes or the living conditions of education professionals. The research aimed to analyze how pedagogical practices are being developed in this pandemic period and how it affects the emotional health in the municipal school teachers in Humaitá-AM. To carry out this research, a qualitative and quantitative approach methodology was adopted, with the application of a virtual interview, in addition to the use of a form available on google. The interviews were made available in several groups of teachers, by schools in a total of nine schools in the urban area of the municipality. These interviews were aimed at teachers who work from the 1st to the 5th of elementary school. It was found that most teachers are developing pedagogical activities, without receiving any type of training or assistance with the use of the internet for the development of activities. The vast majority of teachers consider that the remote

${ }^{1}$ Doutora em Educação. Universidade Federal do Amazonas, Colegiado de Pedagogia, Humaitá/AM - Brasil.

${ }^{2}$ Doutora em Educação. Universidade Federal do Amazonas, Colegiado de Pedagogia, Humaitá/AM - Brasil

${ }^{3}$ Mestranda do Programa de Pós- Graduação em Ensino de Ciências e Humanidades - PPGECH da Universidade Federal do Amazonas, Humaitá/AM - Brasil.

${ }^{4}$ Mestrando do Programa de Pós- Graduação em Ensino de Ciências e Humanidades - PPGECH da Universidade Federal do Amazonas, Humaitá/AM - Brasil. 
model has not contributed positively to student learning, many teachers said they were in a high degree of stress, fear, and depression.

Keywords: Pandemic, Education, Pedagogical practice.

\section{RESUMEN}

Brasil y el mundo están atravesando una grave crisis sanitaria, causada por el COVIC-19, que ha afectado a todos los sectores de la sociedad, ya sea en el ámbito sanitario, económico, social, cultural y educativo. En el Brasil, la pandemia ha afectado directamente al sector educativo, ya sea en la suspensión de las clases presenciales o en las condiciones de vida de los profesionales de la educación. El objetivo de este artículo es analizar cómo se están desarrollando las prácticas pedagógicas en este período de la pandemia y cómo esto afecta a la salud emocional de los profesores de la red municipal de Humaitá-AM. Para esta investigación se adoptó una metodología de enfoque cualitativo-cuantitativo, con la aplicación de una entrevista virtual, además del uso de un formulario disponible en Google. Para la realización de las entrevistas se dispuso de varios grupos de profesores, por escuelas en un total de nueve escuelas en el área urbana de la ciudad. Estas entrevistas estaban dirigidas a los profesores que trabajan de 1 a 5 grado. Se constató que la mayoría de los profesores están desarrollando actividades pedagógicas, sin embargo, no reciben ningún tipo de capacitación o ayuda para el uso de la Internet para el desarrollo de las actividades. La gran mayoría de los profesores consideran que el modelo remoto no ha contribuido de manera positiva al aprendizaje de los estudiantes, muchos profesores declararon que se encuentran en un alto grado de estrés, miedo y depresión.

Palabras clave: Pandemia, Educación, Práctica pedagógica.

\section{INTRODUÇÃO}

O Brasil e o mundo estão passando por uma grave crise sanitária, provocada pela COVID-19, que tem afetado todos os setores da sociedade, seja de saúde, economia, social, cultural e educacional. No Brasil a pandemia tem afetado diretamente o setor educacional, seja na suspensão das aulas presenciais, seja na condição de vida dos profissionais da educação.

A situação de pandemia obrigou a tomar medidas para tentar conter a onda de contágio que assolou o país no período de março a junho de 2020, quando dados do Ministério da Saúde apontavam um grande crescimento no número de pessoas contaminadas e de morte pela COVID-19.

No setor educacional, foi decretada a suspensão das aulas presenciais e apresentada a possibilidade de aulas remotas para atender os alunos que não poderiam frequentar à escola. Essa situação tem afetado tanto alunos como professores e demais profissionais da educação que tiveram que mudar completamente a rotina para se adaptar à essa nova realidade.

Este artigo tem o objetivo de analisar como estão sendo desenvolvidas as práticas pedagógicas nesse período de pandemia e como isso afeta a saúde emocional dos professores da rede municipal de Humaitá-AM. Para a realização desta pesquisa foi adotada uma metodologia de abordagem qualiquantitativa, com a aplicação de entrevista virtual, além do uso de formulário disponível no Google. As entrevistas foram feitas com diversos grupos de professores, por escolas, no total de nove escolas da área urbana do município. Essas entrevistas foram destinadas a professores que atuam do $1^{0}$ ao $5^{\circ}$ do ensino fundamental. Constatou-se que a maioria dos professores se encontra desenvolvendo atividades pedagógicas, sem, contudo, receber qualquer tipo de capacitação ou auxílio com o uso da internet para o desenvolvimento das atividades. A grande maioria dos professores considera que 0 
modelo remoto não tem contribuído de forma positiva para a aprendizagem dos alunos. Muitos professores afirmaram estar em alto grau de estresse, medo e depressão.

\section{EDUCAÇÃO E DESIGUALDADE NO CENÁRIO DE PANDEMIA}

O Brasil se configura por grandes desigualdades econômicas e sociais entre sua população, o que aumenta os problemas sociais como a violência, a pobreza, a fome, a prostituição infantil e juvenil etc. Esses problemas afetam diretamente a permanência e o sucesso dos alunos no processo de educativo, ocasionando gravidez na adolescência, uso e tráfico de drogas nas escolas e o abandono escolar, além de aumento de casos de violência física e verbal como professores e funcionários.

Esse cenário é mais acentuado na população mais pobre. Quando verificamos os níveis de rendimento econômico dessa parcela da população, percebemos que

Conforme mencionado, as atividades econômicas de menores rendimentos médios Serviços domésticos, Agropecuária e Construção - são as que proporcionalmente possuem mais ocupados de cor ou raça preta ou parda. Em 2019, a população ocupada de cor ou raça branca ganhava, em média, $73,4 \%$ mais do que a de cor ou raça preta ou parda, e os homens, $29,6 \%$ mais que as mulheres. Os resultados indicam uma desigualdade estrutural, dado que esses diferenciais, salvo pequenas oscilações, permanecem ao longo de toda a série (IBGE, 2020, p. 33).

Considerando que a educação não se configura como um serviço isolado, pois está no cerne da produção da vida e na construção de novos conhecimentos, é necessário compreendermos a educação como um bem público que necessita ser ofertado alinhado a outras ações e serviços que possam minimizar ou reduzir os fatores que afetam diretamente o processo de escolarização da população jovem desse país. "De fato, a falta de oportunidades, que levava $23 \%$ dos jovens no país a não estarem estudando nem trabalhando em 2017, aliada à mortalidade precoce da juventude em consequência da violência, impõem severas consequências sobre o futuro da nação (IPEA, 2019, p. 6)".

No contexto da pandemia causado pela COVID-19, o mundo se viu diante de um grande dilema. Como oferecer educação sem o espaço físico da escola, pois foi necessário fechar todos os espaços escolares para tentar evitar o aumento de pessoas contaminadas e ainda tentar frear a onda de contágio pela população que tem causado mais 6 milhões de contaminados e cerca de 160 mil mortos em todo o Brasil, uma tragédia humana (CORONAVÍRUS/BRASIL, 2020).

A expansão da pandemia de Covid-19 pelas favelas, periferias e interiores do Brasil escancarou a perversa desigualdade social e econômica entre as classes sociais, naturalizada e aceita por grande parte da sociedade e das instituições do Estado, o que representa uma barreira às recomendações de higiene básica, distanciamento físico e permanência em casa [...] (STEVANIM, 2020, s/p).

No Brasil, não foi diferente. Foi necessário suspender as aulas presenciais nas escolas e universidades e foi decretado o isolamento social como último recurso para frear o aumento exacerbado de contaminação e mortes, pois o Brasil já contabiliza mais de seis milhões de contaminados e mais de cento e sessenta mil mortos, ou seja, estamos realmente diante de uma grave crise sanitária que afeta todos os setores da sociedade (CORONAVÍRUS/BRASIL, 2020, s/p).

A suspensão das aulas presenciais e a possibilidade de aulas remotas, por meio eletrônico, tem evidenciado grande desigualdades sociais, pois muitas famílias não têm acesso regular ao sistema de 
internet. Apesar de dados oficiais apontarem que mais de $50 \%$ da população brasileira possui acesso à telefonia móvel, isso por si só não garante o acesso de boa qualidade ao serviço de internet. Somado à situação econômica da maioria das famílias de menor renda, que por conta da pandemia tiveram seus salários diminuídos e/ou perderam seus empregos formais ou informais, gerando grande transtorno de sobrevivência para uma grande parcela da população brasileira mais vulnerável.

Grande parte da população do mundo não está em condições de seguir as recomendações da Organização Mundial de Saúde para nos defendermos do vírus porque vive em espaços exíguos ou altamente poluídos, porque são obrigados a trabalhar em condições de risco para alimentar as famílias, porque estão presos em prisões ou em campos de internamento, porque não têm sabão ou água potável, ou a pouca água disponível é para beber e cozinhar, etc. (SANTOS, 2020, p. 4).

Com a justificativa de não deixar os alunos sem atendimento escolar, o Ministério da Educação (MEC), o Conselhos de Educação Nacional e os conselhos Estaduais recomendaram que o atendimento escolar fosse realizado de forma remota, através do uso de plataformas específicas, como no caso de algumas escolas privadas, como o Google Classroom e o uso das redes sociais como o facebook, Instagram, whatsapp etc., tentando manter uma comunicação entre a escola e seus alunos nesse momento de distanciamento social. Na prática, isso não apresentou resultado muito positivo, considerando que não podemos vincular o processo de aprendizagem apenas nos referindo aos conteúdos, que por si só já apresentam grandes dificuldades de acesso, mas é necessário considerar que, para além da falta de aulas presenciais, estão imbricadas questões sociais e emocionais que perpassam a vida cotidiana de alunos e professores neste período de pandemia.

Nessa situação, fica mais evidente a falta de políticas públicas para proporcionar aos profissionais da educação condições de capacitação e de acesso às novas tecnologias como uma ferramenta de ensino no processo educativo formal. É notório que a popularização faz uso das redes sociais como ferramenta de comunicação, mas o Brasil ainda não conseguiu estabelecer uma realidade escolar que, de fato, esteja conectada nas ferramentas tecnológicas atuais no campo educacional. Assim,

O que estamos acelerando é uma nova sociedade baseada em uso intensivo de tecnologias, o que alguns chamam de sociedade 5.0, onde o foco não recai apenas nas tecnologias, mas na sociedade que está inserida em um determinado ambiente e que vai ser impactada pelas novas tecnologias. O sucesso de uma nova tecnologia depende do uso que a sociedade faz da mesma, no caso em que estamos vivendo, todas as tecnologias que possam ser utilizadas para reduzir o impacto do isolamento social exigido pela pandemia serão consideradas bem-vindas, benéficas e de sucesso (SCHNEIDER; SCHNEIDER, 2020, 52-53).

A tecnologia da informação pode ser utilizada como um recurso, mas não como um fim na educação, principalmente na educação básica, período em que os estudante estão na formação primária e devem ser acompanhados pelos pais e professores, além do desenvolvimento emocional e social que se estabelece na convivência com outros estudantes e os profissionais da educação. Com isso, é necessário "reestruturar os sistemas educacionais por dentro, superando o ensino baseado em conteúdos antigos pouco funcionais, obtendo, assim, uma sociedade não apenas eficiente, mas também justa, democrática e inclusiva" (GIMENO SACRISTÁN et al., 2011, p. 8).

Nesse sentido, a pandemia colocou a educação em suspense, era preciso encontrar uma solução rápida para atender minimamente os estudantes que não podem mais acessar a escola e professores que repentinamente se viram obrigados a se adaptar a uma nova realidade no método de ensino. 
Como o Brasil tem dimensões continentais, as disparidades entre as diversas regiões e estados brasileiros evidenciou a desigualdade estrutural que assola esse país. A pandemia não é tão democrática, como alguns afirmam. $O$ vírus pode até não selecionar os que serão contaminados, mas com certeza o acesso ao atendimento médico de qualidade não está disponível para a grande maioria da população brasileira. Isso, também, se apresenta com relação ao acesso à educação em tempo de pandemia. Para grande parte dos estudantes da rede privada, o ensino remoto foi amplamente utilizado e, de fato, a grande maioria tinha as ferramentas necessárias para acessá-lo. Enquanto os pobres, morados de favelas, ribeirinhos, indígenas, população de rua, dentre outros não conseguiram acessar de forma satisfatória esse modelo de aprendizagem.

Para os professores, a experiência profissional tem sido muito dolorosa, pois muitos não dispõe de internet de boa qualidade em suas residências para preparar aulas e utilizar ferramentas tecnológicas atuais, tampouco formação tecnológica capaz de atender esse novo modelo de ensinar. Não significa que todos os professores são resistentes às novas situações de aprendizagem, mas precisamos compreender que quando não dominam o processo, se torna mais difícil operacionalizar a prática pedagógica.

Assim, iremos abordar na seção seguinte a realidade vivenciada por professores-educadores de um município localizado no Sul do Estado do Amazonas.

\section{TRABALHO PEDAGÓGICO EM TEMPOS DE PANDEMIA: REALIDADE VIVENCIADA POR PROFESSORES MUNICÍPIO DE HUMAITÁ-AM}

O Estado do Amazonas compõe uma das unidades federativa do Brasil. Situado na região Norte, é considerado o maior estado do país em extensão territorial e possui a maior biodiversidade do mundo. Com 62 municípios, estima-se que sua população é de mais de 4 milhões de habitantes.

O município de Humaitá encontra-se localizado na Mesorregião do Sul do Amazonas e microrregião do Madeira. Conforme estimativas do Instituto Brasileiro de Geografia e Estatística (IBGE), a população em 2010 era de 44.227, sua população estimada em 2019 é de 53.383 habitantes.

Segundo Franco (2018), a economia de Humaitá-AM baseia-se no cultivo de mandioca, arroz, milho, feijão, cupuaçu, banana e hortaliças; a pecuária de bovinos; a piscicultura; a pesca artesanal; o artesanato; a atividade de beneficiamento da castanha; a extração de madeira e de ouro encontrado no Rio Madeira, bem como a caça e a pesca.

O município de Humaitá é cortado por duas rodovias federais, a BR 230 - Transamazônica e a BR 319, que são os principais meios de acesso ao município. Ao longo destas rodovias, encontram-se alguns assentamentos rurais e a disputa por terra é bastante conflituosa.

No setor educacional, o município possui rede pública e privada. A rede pública estadual atende 0 Ensino Fundamental II e o Ensino Médio. A Educação Infantil e o Ensino Fundamental I ficam sob a responsabilidade do município que atende a zona urbana e rural, com grande percentual de escolas localizadas nas áreas rurais.

O Estado do Amazonas foi bastante atingido pela contaminação do COVID-19 e muitos casos de mortes ocorreram, causando medo e pânico em sua população. Diante da calamidade, a Secretaria de Estado de Educação e Desporto, através da Portaria GS nº 311 de 20 de março de 2020, suspendeu 
as aulas presenciais e resolveu instituir no âmbito da rede pública de ensino do Amazonas, o regime de aulas não presenciais nos níveis, etapas e modalidade da Educação Básica enquanto houver necessidade (DOEA, 2020, p.7).

Nesse momento, a SEDUC-AM passou a oferecer aulas remotas via internet ou pelo canal de televisão para todo o Amazonas. Mas durante essas transmissões, o sinal não chega com boa qualidade a todos os municípios e região metropolitana de Manaus. Isso gerou muitos problemas para os professores, estudantes e suas famílias.

No município de Humaitá-AM, a prefeitura decretou a suspensão das aulas presenciais, ficando a cargo da escola e dos seus professores a elaboração de aulas, vídeos e atividades que eram disponibilizadas, principalmente, via WhatsApp, mas essas experiências tornaram-se ineficaz e muitos professores passaram a oferecer apostilas com material para estudo.

De acordo com os calendários escolares disponibilizados pela Secretaria Municipal de Educação de Humaitá-AM, as aulas foram iniciadas no dia 18 de fevereiro de 2020. Em 18 de marco de 2020, é publicado o decreto municipal Decreto No 056/2020 que dispõe sobre a situação de emergência na saúde pública deste município em razão da COVID-19. Além disso, criou-se um Comitê Intersetorial de Enfrentamento e Combate à COVID-19 que suspende as aulas presenciais em todo o município de Humaitá (HUMAITÁ, 2020) a partir de 18 de março de 2020.

Diante dessa realidade, resolvemos realizar um estudo para tentar compreender como essa nova situação de ensino e aprendizagem está sendo desenvolvida e como tem afetado a prática pedagógica e saúde emocional dos professores.

Nesse sentido, elaboramos uma entrevista no Google formulário e disponibilizamos em todos os grupos de WhatsApp das escolas urbanas para que fosse respondido. Esse formulário não foi disponibilizado para os professores do campo, pois até mês de outubro não estava sendo realizada atividade escolar com os estudantes das escolas localizadas no contexto rural.

Na rede municipal urbana existem nove escolas localizadas na sede do município com cerca de 53 professores (SEMED, 2020) do $1^{\circ}$ ao $5^{\circ}$. Responderam a entrevista online (formulário) 31 professores que se disponibilizaram, com o seguinte perfil: todos que responderam são efetivos, provavelmente porque os professores temporários não iniciaram o ano letivo. Quanto ao sexo, a grande maioria é do sexo feminino, com cera de $75 \%$, na educação dos anos iniciais. Quanto à idade, os pesquisados têm entre 33 a 56 anos e o tempo de serviço varia entre três anos e mais de vinte anos, isso demonstra que a grande maioria dos professores possui muita experiência no magistério. Segundo Gomes (2010), muitos estudos sobre como se consolida a constituição do ser professor afirmam que a maioria adquiriu identidade de ser professor dentro do ambiente escolar, a partir de suas experiências com seus alunos e com os demais professores.

Com relação à formação profissional, todos os professores possuem graduação na área, alguns com pós-graduação, isso revela um dado relevante se considerarmos o investimento na formação de professores neste município. Em relação à carga horária de trabalho, 65\% afirmaram que possuem 40 horas semanas de trabalho.

Com relação à prática pedagógica dos professores em tempo de pandemia, fizemos algumas indagações: como você tem desenvolvido seu trabalho em tempo de pandemia? Responderam: 
Aulas remotas (P. 1).

Orientação e aplicação das atividades através da família, por meio do wattsap e ou telefone (P. 4).

Trabalho pelo celular nos grupos escolares do zap (P. 12).

Tenho buscado atividades que facilitem aos alunos a compreensão dos conteúdos que são passados para eles, através de apostilas mensais (P. 17).

Através do grupo de Whatsapp da turma, todos os dias envio os conteúdos para que os pais oriente seus filhos nas atividades (P. 27).

Como podemos verificar, os professores estavam utilizando a plataforma do whatsapp para enviar as atividades que eram elaboradas, alguns fizeram vídeos para enviar aos seus alunos. Outro problema eminente anunciado pelos professores é que muitas famílias possuem apenas um aparelho celular para atender todos os filhos (em geral, três ou quatro filhos), o que tem causado uma certa ausência dos alunos nas aulas. Mas a grande maioria dos professores não demonstrou conhecimento específico de tecnologia para utilização de outras plataformas digitais, talvez isso possa ser discutido após o retorno para as escolas, como forma de integrar essas ferramentas como objetivo pedagógico voltado ao ensino e à aprendizagem dos alunos. Pois existem alguns programas governamentais que apoiam o uso das novas tecnologias educacionais, mas não existe um incentivo institucional para a capacitação desses profissionais, o que causa muita apreensão no fazer pedagógico.

Os professores, por sua vez, muitas vezes não sabem como enfrentar esse novo cenário; assim, além de suportarem a precariedade socioeconômica que assola a profissão em boa parte do planeta, têm que lidar com as aflições suscitadas pelos questionamentos acerca do significado do seu trabalho e com a dificuldade crescente de estar à altura do desafio (SIBILIA, 2012, p. 65).

Em seguida, perguntamos sobre o acompanhamento técnico-pedagógico. Muitos professores entenderam apenas o acompanhamento pedagógico em relação à aprendizagem ou aos conteúdos. A grande maioria não respondeu sobre o acompanhamento técnico para melhor utilização de plataformas digitais na elaboração das aulas.

Os professores também necessitam de capacitação adequada e frequente em relação ao uso das novas tecnologias da comunicação e da informação para melhor desempenhar suas atividades, mesmo em tempos "normais", a capacitação em relação tecnologia digital é fundamental para que a escola acompanhe as novas ferramentas utilizadas por seus alunos e consiga o melhor aproveitamento no processo de aprendizagem.

Quando perguntamos em relação à participação de seus alunos, como você interage com eles? A maioria dos professores demonstrou muita preocupação com os alunos.

Dê diversas maneiras. Sempre tenho que lembrar que eles são crianças, apesar das aulas serem online, tenho que selecionar músicas com gestos, histórias infantis e vídeos das aulas que chamem a atenção deles no seu aprendizado, quando isso não acontece, mudo para outro (P. 17).

Eles conversam comigo no privado quando tem dúvidas ou pra me enviar atividades no privado (P. 22).

Através de vídeo aula, áudio informativo (P. 21). 
A relação professor-aluno vai muito além do ensinar e aprender conteúdos, existem relações afetivas e de confiança que são estabelecidas durante a convivência na escola. Isso é muito importante para que o aluno possa se sentir seguro e protegido dentro do ambiente escolar.

Com relação à participação dos pais ou responsáveis pelos alunos, muitos professores afirmaram que a maioria não acompanha as atividades, seja por não reconhecer a importância da aula online nesse momento, seja por não disponibilizar de tempo e conhecimento para dar suporte às crianças. Essa situação já é muito vivenciada no cotidiano escolar, mas a situação de pandemia pode ter acelerado mais esse processo pois, muitas famílias viveram ou vivem o drama da perda de seus familiares e amigos, enfrentando grandes dificuldades econômicas e muitas vezes o aumento da violência doméstica que afeta todos os membros da família. Outra situação relatada foi quando questionamos sobre a eficácia das aulas remotas, a maioria dos professores afirmou que prefere criar apostilas, pois muitos alunos não participam das aulas remotas.

Diante dessa situação de grave crise sanitária que obrigou todos a adaptarem suas rotinas de trabalho, perguntamos aos professores: você considera a COVID-19 uma grave doença? Todos afirmaram que sim. Com relação ao trabalho desenvolvido, a maioria considerou que seu trabalho enquanto professor aumentou muito, pois muitos pais não respeitam o horário de aula e mandam mensagem a qualquer hora do dia e da noite, isso tem atrapalho muito a vida pessoal dos professores. Nesse sentido,

[...] cabe à escola, neste momento, provar que suas estruturas não são tão rígidas, e que a palavra de ordem é a flexibilidade, por meio de projetos adaptados à situação, envolvendo a leitura de bons livros, filmes, situações de aprendizagem vinculadas à experiência social de isolamento e enfrentamento de uma pandemia mundial, questões que independem de um currículo rígido, demonstrando às escolas que os desafios às crianças são de outra ordem (OEMESC, 2020, s/p).

Com relação ao nível de estresse, 40\% consideraram alto, 45\% nível médio e 15\% afirmaram que seu nível de estresse é baixo. Outra indagação está relacionada ao retorno escolar. Perguntamos se os professores consideram seguras as condições sanitárias das escolas e da rede de saúde para o retorno das aulas presencias, a grande maioria se posicionou afirmando que o município não oferece condições sanitárias adequadas para promover o retorno às aulas presenciais, pois não dispõe de condições sanitárias eficientes.

Percebemos que nas entrevistas com alguns professores, demonstraram muita preocupação, estavam se questionando sobre a permanência das aulas online e defenderam o uso de apostilas como a melhor opção para os alunos.

\section{CONSIDERAÇÕES FINAIS}

A crise sanitária causada pela COVID-19 colocou todos em situação de alerta. A humanidade se viu diante de um "monstro" que não conseguia controlar. Essa situação causou um estado de pandemia e todos os países foram obrigados a tomar medidas de controle para tentar evitar o contágio em massa. No Brasil, a pandemia já registrou mais de 160 mil mortos, milhares de contaminados e uma situação grave na saúde tem demonstrado que as desigualdades sociais e econômicas aprofundam as diferenças no atendimento e na recuperação dos infectados.

Diante dessa situação, o Brasil foi obrigado a decretar situação de calamidade e adotou diversas medidas para o enfrentamento desta crise sanitária. Uma das medidas foi a suspensão das aulas 
presenciais. Isso não foi diferente no Estado do Amazonas e no município de Humaitá, que também suspendeu as aulas.

Com isso, os professores passaram a realizar atividades de forma remota, principalmente, utilizando as mídias digitais como o WhatsApp. Percebemos que os professores não têm recebido apoio e suporte técnico para desenvolver atividades escolares com seus alunos.

As atividades foram restritas ao uso do celular, não sendo utilizada outras plataformas como o Google Class, ou Google Met. Devemos considerar que muitos pais não possuem familiarização com essas plataformas e que na maioria das vezes existe um aparelho celular para atender três ou quatro filhos.

Os professores consideram a COVID-19 uma doença grave, não concordam com o retorno imediato das aulas presencias, pois, o município não oferece as condições de segurança sanitária. Outro problema está relacionado à vida pessoal dos professores, pois muitos enfatizaram que estão com a rotina profissional muito alterada, considerando que o canal de comunicação com os pais é o celular, muitos pais não respeitam o período de descanso dos professores e isso tem aumentado o nível de estresse desses profissionais.

Enfim, apesar de estarmos um uma situação extremamente atípica, consideramos que os professores ainda mantêm o compromisso com seus alunos e estão se esforçando para realizar um trabalho pedagógico.

\section{REFERÊNCIAS}

BRASIL, Ministério da Educação - Secretaria de Educação Fundamental. Parâmetros Curriculares Nacionais: Ciências Naturais. Brasília:1997.

IBGE - Instituto Brasileiro de Geografia e estatística. Síntese de indicadores sociais: uma análise das condições de vida da população brasileira. Rio de Janeiro: IBGE, 2020. Disponível em: https://biblioteca.ibge.gov.br/visualizacao/livros/liv101760.pdf. Acesso em: 16 nov. 2020.

CORONAVÍRUS/BRASIL. Ministério da Saúde. Brasília, 2020. Disponível em: https://covid.saude.gov.br/. Acesso em: 21 nov. 2020.

DOEA - Diário Oficial do Estado do Estado do Amazonas, 23 de março de 2020. Disponível em: file://C:/Users/Usuario/Desktop/DOSSI\%C3\%8A/Portaria-n-311-de-20-de-mar\%C3\%A7o-de2020-GS-Secretaria-de-Estado-e-Educa\%C3\%A7\%C3\%A3o-e-Desporto-Institui\%C3\%A7\%C3\%A3ode-regime-especial-de-aulas-nao-presenciais-como-preven\%C3\%A7\%C3\%A3o-a-pandemia-COVID19_.pdf. Acesso em: 14 out. 2020.

GIMENO SACRISTÁN, José et al. Educar por competências: o que há de novo. Porto Alegre: Artmed, 2011.

GOMES, Ana Clara. Constituir-se professor: a influência da história de vida e das práticas pedagógicas na formação docente. In: SEMINÁRIO DE PESQUISA DO NUPEPE, 2., 2010, Uberlândia. Anais... [S.I.: s.n.], 2010.

HUMAITÁ, Decreto No 056/20 do gabinete do Prefeito, 2020. 
IPEA - Instituto de Pesquisa Econômica Aplicada. Atlas da violência. Brasília: DF, 2019. Disponível em: https://www.cidadessaudaveis.org.br/cepedoc/wp-content/uploads/2020/04/Livro-BoaventuraA-pedagogia-do-virus.pdf. Acesso em: 12 nov. 2020.

OEMESC - Observatório do Ensino Médio em Santa Catarina, 2020. Disponível em: https://www.udesc.br/arquivos/udesc/id_cpmenu/7432/EDITORIAL_DE_ABRIL__Let_cia_Vieira_e_ Maike_Ricci_final_15882101662453_7432.pdf. Acesso em: 15 nov. 2020.

SANTOS, Boaventura S. A cruel pedagogia do vírus. Coimbra: Edições Almedina, 2020. Disponível em: http://anpocs.org/index.php/publicacoes-sp-2056165036/boletim-cientistassociais/2367-boletim-n-46-cientistas-sociais-e-o-coronavirus. Acesso em: 14 out. 2020.

SCHNEIDER, Elton Ivan; SCHNEIDER, Alice Braun. Educação em tempos de pandemia. In: MACHADO, Dinamara Pereira (org.). Educação em tempos de COVID-19: reflexões e narrativas de pais e professores. Curitiba: Editora Dialética e Realidade, 2020. p. 51-64.

SEMED - Secretaria Municipal de Humaitá. 2020.

SIBILIA, Paula. Redes ou Paredes: a escola em tempos de dispersão. Rio de Janeiro: Contraponto, 2012.

STEVANIM, Luiz Felipe. Reportagem questiona: Ficar em que casa? Fundação Fiocruz, reportagem publicada no 13/05/20. Disponível em: https://portal.fiocruz.br/noticia/desigualdadesocial-e-economica-em-tempos-de-covid19\#: : :text=A\%20expans\%C3\%A30\%20da\%20pandemia\%20de,\%C3\%A0s\%20recomenda\%C3\% A7\%C3\%B5es\%20de\%20higiene\%20b\%C3\%A1sica\%2C. Acesso em: 16 nov. 2020. 